\title{
World Health Situation after September 11, 2001
}

Benjamín Ruiz Loyola

Department of Organic Chemistry, Faculty of Chemistry, Unam

*Corresponding Author: Benjamín Ruiz Loyola, Department Of Organic Chemistry, Faculty of Chemistry, Unam

Received date: July 20, 2021; Accepted date: August 14, 2021; Published date: September 07, 2021

Citation: Benjamín R. Loyola. (2021 World Health Situation after September 11, 2001. J. Gastroenterology Pancreatology and Hepatobilary Disorders. 5(4) DOI: 10.31579/2641-5194/041

Copyright: () 2021, Benjamín Ruiz Loyola, This is an open access article distributed under the Creative Commons Attribution License, which permits unrestricted use, distribution, and reproduction in any medium, provided the original work is properly cited.

Abstract
Has the global health situation improved, worsened or remained at the same level,
after the attack on the twin towers in 2001 ? We make a brief analysis of some
epidemiological outbreaks that have arisen in these twenty years, their consequences
and what could come in the future.
Key Words: anthrax; cholera; AH1N1; AH5N1; SARS; MERS; SARS-CoV-2;
mortality; vaccines;

\section{Introduction}

Following the fall of the Twin Towers on September 11, 2001, a series of anthrax attacks were reported through the United States Postal Service. According to the AMERITHRAX INVESTIGATIVE SUMMARY prepared by the FBI and published on February 19, 2010 [1] (yes, almost 9 years later), there were at least five contaminated envelopes addressed to different recipients: Senators Thomas Daschle and Patrick Leahy, the New York Post and NBC journalist Tom Brokaw. As a result of handling these envelopes, people became ill, from cutaneous anthrax and from pulmonary anthrax. Of these last victims, who fell ill when inhaling the spores of the bacteria, five died from the infection caused. The investigation led to the blame on Dr. Bruce E. Ivins, a military researcher with a specialty in microbiology assigned to the United States Army Biodefense Laboratory at Fort Detrick, Maryland.

Unfortunately, Dr. Ivins passed away before the trial. Some reports indicate that the amount of work he had, and the pressure exerted against him by the FBI led him to suicide [1], while others (such as the website of the Moscow daily Pravda [1]) attribute his death to the Israeli agency Mossad.

One of the immediate consequences of both the attack in New York and the spread of anthrax was the issuance of the Law against bioterrorism in 2002 (Bioterrorism Act 2002), which imposes very strict measures for the importation of consumer products and agricultural inputs in the United States, to prevent the entry of infected food into United States territory. Despite this, outbreaks of E. Coli infection in food have occurred in the United States at different times. For example, in 2006 there was an outbreak originating in spinach grown in California, prompting Canada to issue a health alert against US spinach. That same year there was another outbreak of the same type, now originating in Taco Bell restaurants in the northwest of that country, which was found in contaminated onions. A few days later another chain, Taco John's, had the same problem. The onions were traced and found to have apparently come from a farm in Southern California. In addition, lettuces that presumably could be contaminated with the same bacteria were removed, but in October 2006 it was found that 250 boxes of those lettuces were lost. For its part, in 2011 there was an outbreak of the same bacteria in Germany; cucumbers of Spanish origin were initially blamed but later reversed. At the beginning of July, almost 4,000 infected people and more than 50 deaths were reported in 14 European countries in addition to one case in Canada and six in the United States, with one death in the latter country. The European Food Safety Authority issued a report in that same July, which stated that the contamination was found in vegetable sprouts (including mustard and fenugreek) from seeds acquired in Egypt between 2009 and 2010. Despite the bioterrorist act , E. coli bacteria from Europe entered the United States and the biggest problems they had arose from within its territory, not from outside. This must be taken into account, due to the impact it represents on the free trade of various food products between the United States and the rest of the world.

\section{New Epidemic Outbreaks}

In the period under study, several new outbreaks with both novel and very old microorganisms have been detected. Let's talk about some of them.

\section{AH5N1}

In 2003, a relatively novel disease appeared that attracted attention and after a few months caused a global alert: the so-called avian flu or influenza A H5N1, which has not been eradicated. Although it has only 
been identified in 15 countries, the transit of people around the world has implied the need to maintain epidemiological surveillance. The outbreak started in Vietnam, moved to Thailand, and then most of Asia had reported cases. What is worrying is the high number of deaths which represents a mortality rate of $58.5 \%$. The symptomatology associated with the onset of this disease differs very little from that associated with human influenza and is summarized in cough, sore throat, muscle pain, with the subsequent appearance of eye infection, pneumonia, respiratory collapse and eventually death. The main cause of infection in humans is contact with infected birds, especially poultry. It is easy to understand that for this reason there are worldwide restrictions on the trade of this type of meat from the countries involved.

\section{SARS}

In 2003 there was a world alert with another respiratory disease that also originated in Asia, the Severe Acute Respiratory Syndrome SARS. It left China and spread to various countries, infecting a total of 8,422 people worldwide, of which 916 died, or $10.9 \%$. It is notable that there were a greater number of patients, although a much lower mortality. These two diseases kept the world tense for a long time. The World Health Organization established that the SARS outbreak period lasted from November 2002 to November 2003 and was mainly located in China, Canada, Mongolia, the Philippines, Singapore and Vietnam, although cases were reported elsewhere, such as Australia , Belgium, France, Germany, Italy, Ireland, Romania, Switzerland, Thailand, the United States and the United Kingdom. China took all kinds of measures to identify the pathogenic organism and to control it, from the establishment of quarantine zones in train stations and airports to the total isolation of entire villages, prohibiting the entry and exit of people who did not have a government pass, as happened, for example, in Hebei province from April 21 to May 13, 2003 [1]. In the end, the disease has been kept under control but it has not been eradicated.

However, there is a new cause for concern: a team of scientists from Germany has identified a virus very similar to the one that causes SARS in some colonies of bats and their feces, which opens up a new possibility for the spread of this type of virus [1].

\section{CHOLERA}

Of the most serious cases of international epidemics that occurred in the interval under study (2001-2021) is that of Haiti; After the terrible earthquake that struck the country on January 12,2010, a cholera epidemic of enormous proportions broke out. In December of that same year, eleven months after the earthquake, there were more than 93,000 infections and 2,120 deaths from this disease, an average of more than 6 deaths a day. One of the possible causes of the spread of this disease was located in a group of UN peacekeepers from Nepal and a peacekeeping mission in Haiti, according to a report by French epidemiologist Renaud Piarroux. There were lynching of people accused of witchcraft related to the disease, as well as being carriers of it; the peacekeepers themselves were at high risk for this reason (In Mexico, the cholera health alert was established until November 2010 and in April 2011 this disease was detected in a 10-year-old girl, the first case in several years. It is not known whether it corresponds to the Haitian strain or a different one).

\section{The Problem of Vaccines and Vaccine Abuse}

Several diseases that were considered controlled or well defined, have been spreading throughout the world in the early 21 st century. Among others, mention may be made of tuberculosis, whooping cough, measles, malaria, diphtheria, and viral hepatitis.

In 2011, there was a measles outbreak in the United States and Europe that put the Mexican health authorities on alert (until June of that year there were 127 cases registered in the United States and 21,326 in 30 European countries); the secretary of health, José Ángel Córdoba pointed out that there was a strategy to face this alert, starting with training doctors in its diagnosis and treatment, because since 2007 there had not been a case in Mexican territory. This health strategy, in addition to training, included vaccination of Mexican customs personnel, as well as aircraft crews and health personnel; have a presence at international airports to detect infected passengers; tell passengers about immediate symptoms and launch a vaccination campaign for the population between 12 and 39 years of age who have not received a booster of the vaccine. The latter posed a problem, because official estimates projected a population of close to $1,800,000$ susceptible inhabitants and there were at that time (July 4) only one million doses.

This disease is preventable through vaccination; But some events, some recent and others less so, are food for thought and have complicated the global picture of vaccination. Mention should be made, for example, of research that linked some vaccines (the triple, against mumps, measles and rubella) with the appearance of autism in children. The lead author, Andrew Wakefield, was found to be associated with a law firm that raised lawsuits against vaccine manufacturers. As a result, the Lancet magazine, in which the original work was published, retracted ${ }^{\mathrm{i}}$ and accepted that it should never have been published; while Wakefield lost his medical license in the United Kingdom, although he continued to practice in the United States.

But the damage was done; from that publication (1998) a furious campaign against all types of vaccines was unleashed, which has caused a huge lack of confidence. Diseases that could be controlled, such as hepatitis and polio, have resurfaced relatively recently. For example, in 2003 there were 784 cases of polio worldwide, but in 2004 there were 793 in Nigeria alone. The numbers go up and down but the disease is still there.

The measles situation is very similar. We already talked about the situation around 2011; in 2018 there were more than 140,000 deaths from this cause, globally, despite the wide distribution of vaccines ${ }^{\text {ii. }}$. The United States CDC reports, as of July 2021, that the 10 countries with the most reported cases of measles are those shown in table 1. 


\begin{tabular}{|l|l|l|}
\hline Rank & Country & Number of Cases \\
\hline 1 & Nigeria & 5,300 \\
\hline 2 & Pakistan & 4,868 \\
\hline 3 & India & 1,865 \\
\hline 4 & Niger & 1,58 \\
\hline 5 & Democratic Republic of the Congo & 1,495 \\
\hline 6 & Burkina Faso & 1,243 \\
\hline 7 & Afghanistan & 1,129 \\
\hline 8 & Bangladesh & 917 \\
\hline 9 & United Republic of Tanzania & $\mathbf{9 0 2}$ \\
\hline 10 & Côte d'Ivorie & $\mathbf{8 8 8}$ \\
\hline
\end{tabular}

Table 1.Data covers from December 2020 to July 2021 iii.

It is not surprising that these countries are located in Africa, Asia and the Middle East. On many occasions, religious reasons are adduced for denying vaccines to the population: in 2003 a group of religious in northern Nigeria began to preach against vaccines, arguing that far from being a protective act of children, it was about a covert campaign by Western powers to sterilize and kill children. For this reason, there was an increase in polio cases in Nigeria for 2004. This led in 2009 to Barack Obama, president of the United States, addressing a speech to the Muslim world to try to convince them that his intentions were good. In one part of his speech, Obama mentioned that he would begin a new effort with the Islamic Conference to eradicate polio and expand its sponsorship in Islamic communities to promote maternal and child health. And he requested that they be made together, Muslims and North Americans. However, some events attract a lot of attention; It was published that the CIA, in an effort to collect genetic material (DNA) from relatives of Osama Bin Laden, carried out a false vaccination campaign against hepatitis in Pakistan ${ }^{\text {iv }}$, with the help of a doctor who later was arrested (Shakil Afridi). The serious thing about the matter is that it was a very low-income population sector that was affected by this act, which will cause even greater resistance to vaccination and, therefore, a resurgence of diseases that should already be controlled and in the process of disappearing. Is this double standard acceptable, this double discourse of the most powerful nation in the world towards the rest of the planet? There is no doubt that they will do it again if it suits them and the question remains: how many times have they done it before?

It seems to us that this is an act that will have serious repercussions, and causes fear and indignation. The country that claims to be a staunch defender of human rights, playing at its convenience with the right to health that assists every human being!. How illustrative!

\section{SARS-COV-2}

Now, the current SARS-CoV-2 pandemic that causes the disease known as COVID-19, which has lasted for more than a year and a half (at the time of writing this article), seems to be far from being controlled; Despite the speed to develop and apply vaccines, we are far from a situation of control; some countries have a majority of their population vaccinated, although with the appearance of new varieties of the virus (or mutations), infections continue. The economically less favored nations are a long way from vaccines and distribution, in many cases, does not include the most vulnerable population, but the best politically connected. It seems to be the never ending story. It should also be considered that, despite the massive vaccination, the vaccines have been authorized to be applied as an emergency measure, but they do not imply absolute safety and efficiency, we are simply facing an intensive investigation of phase three of them, as would happen with any other medication.

And the next consideration is that the experts assure that without a doubt in the future we will have to face a much stronger pandemic than the present one, based on the fact that the mortality caused by this virus does not compare with its relatives SARS and MERS. One publication estimates the different mortalities at $4.2 \%$ for SARS-CoV-2, $11 \%$ for SARS and $34 \%$ for MERS ${ }^{v}$, while others place between 2 and $4 \%$ for SARS-CoV-2, 10-15\% for SARS and 37\% for MERS ${ }^{\text {vi }}$. Even with these differences, what can be seen is that a pandemic that will be located at a mere $25 \%$ mortality, and seeing how the entire world has lived the pandemic between 2020 and 2021, the prospects are not very pleasant.

\section{Conclusion}

What has been seen in the previous pages makes it clear to us that, in terms of health, we are no better than before September 11, 2001. Already controlled diseases that reappear, strong opposition to vaccination campaigns that could help to control them (whether for reasons religious or other), together with the lies discovered recently, and the coronaviruses discovered after that date, make us foresee complicated situations in this area, at least in the coming years. The speed for scientists around the world to develop new and better vaccines, sometimes tailored to the pathogenic microorganism to be controlled, will not be enough if effective international mechanisms are not in place to deliver vaccines to the entire world population; the COVAX mechanism created for an equitable distribution of vaccines among all countries has not been very effective. And US law continues to hamper free trade in agricultural products, as we mentioned in the introduction. Clinical research must continue in an accelerated rhythm, to be able to count with drugs suitable to be used against any microbiological new diseases that emerge in the future, as well as in the vaccine field. Global warming is one source of trouble, because of the environmental effects, the search for new environments for species not in contact with humans before, but that in the last years (and in the years to come) will be making an intense contact. So, many viruses safely found in some species, might be mortal for the human being; the problem is, then, not only a health one, but also an environmental issue (a matter of earth's health). Let's be prepared for rough times.

\section{Acknowledgement}

To Jorge Benjamín Ruiz Gutiérrez, for his invaluable collaboration in this research. 


\section{References}

1. http://www.thelancet.com/journals/lancet/article/PIIS01406736\%2897\%2911096-9170/fulltext\#article_upsell

2. https://www.who.int/news-room/fact-sheets/detail/measles

3. https://www.cdc.gov/globalhealth/measles/data/global-measlesoutbreaks.html

4. http://www.guardian.co.uk/world/2011/jul/11/cia-fakevaccinations-osama-bin-ladens-dna,

http://www.nytimes.com/2011/07/12/world/asia/12dna.html?_r= 1
5. Hu, T., Liu, Y., Zhao, M., Zhuang, Q., Xu, L. and He, Qingnan, (2020) A Comparison of COVID-19, SARS, and MERS, Peer J 8:e9725, DOI 10.7717/peerj.9725.

6. Abdelghany, T. M., Ganash, M., Bakri, M. M., Qanash, H., AlRajhi, A. M. H. and Elhussieny N. I., (2021) CARS-CoV-2, the other face to SARS-CoV and MERS-CoV: Future predictions, Biomedical Journal 44, 86-93. 